\title{
Additive and synergistic effects of arbuscular mycorrhizal fungi, insect pollination and nutrient availability in a perennial fruit crop
}

\author{
Ke Chen *, David Kleijn, Jeroen Scheper, Thijs P.M. Fijen \\ Plant Ecology and Nature Conservation Group, Wageningen University, Droevendaalsesteeg 3a, 6708PB Wageningen, The Netherlands
}

\section{A R T I C L E I N F O}

\section{Keywords:}

Arbuscular mycorrhizal fungi

Ecological intensification

Fertilizer

Interaction

Insect pollination

\begin{abstract}
A B S T R A C T
Managing ecosystem services might reduce the dependence of modern agriculture on external inputs and increase the sustainability of agricultural production. Insect pollinators and arbuscular mycorrhizal fungi (AMF) provide vital ecosystem services for crop production, but it has not been tested whether their effects on crop yield interact and how their effects are influenced by nutrient availability. Here we manipulated insect pollination, AMF inoculation and fertilizer application (four levels) in a randomized complete block design with potted raspberry (Rubus idaeus L.) to assess the interacting effects of these variables on crop yield. AMF inoculation increased the per-plant flower number by $33 \%$ and the fruit number by $35 \%$, independently from insect pollination and fertilizer application. Single berry weight furthermore increased more strongly with fertilizer application rates in AMF inoculated plants than in non-inoculated plants. As a consequence, AMF inoculation boosted raspberry yield by $43 \%$ compared to non-inoculated plants. AMF inoculation increased pollinator visitation rate per plant under intermediate fertilizer levels, suggesting additional indirect effects of AMF inoculation on yield. Fruit yield of pollinated plants increased more strongly with fertilizer application rate than the yield of plants from which pollinators had been excluded. At maximum nutrient availability, the combined benefits of both ecosystem services resulted in a $135 \%$ higher yield than that of fertilizer-only treatments. Our results suggest that the benefits of ecosystem services on yield can be additive or synergistic to the effects of conventional management practices. Intensive, high-input farming systems that do not consider the potential adverse effects of management on ecosystem service providing species might risk becoming limited by delivery of ecosystem services. Proactively managing ecosystem services, on the other hand, has the potential to increase crop yield at the same level of external inputs.
\end{abstract}

\section{Introduction}

Agriculture depends on a wide array of ecosystem services (Costanza et al., 1997; Klein et al., 2007), but agricultural inputs like fertilizer have adverse effects on the species providing those services and on the wider environment (Bakhshandeh et al., 2017). Ecological intensification has been put forward as a promising way to make agriculture more sustainable and reduce negative impacts on the environment (Bommarco et al., 2013; Kleijn et al., 2019). This approach proposes to manage for biodiversity to complement or (partially) replace external inputs with production-supporting ecosystem services. Although ecological intensification is increasingly being advocated by scientists and policymakers as an environmentally friendly way towards food security (Pywell et al., 2015; IPBES et al., 2016), it is rarely adopted by farmers (Kleijn et al., 2019). Farmers manage complex agro-ecosystems, with the interplay of several agronomic and environmental factors shaping crop yield. Evidence that a single ecosystem service has a positive effect on crop yield might not be convincing enough for farmers to change their day-to-day practices (Dainese et al., 2019; Kleijn et al., 2019). Ecological intensification might be more appealing to farmers when multiple ecosystem services together can synergistically enhance crop yield. This requires insight into the effects of multiple ecosystem services on crop yield simultaneously, whether and how these services interact and how their benefits are influenced by conventional agricultural practices. However, we are only just starting to understand how multiple ecosystem services might interact (Garibaldi et al., 2018; Tamburini et al., 2019), and we know even less how these interactions are being influenced by agricultural management. Here we contribute to addressing this knowledge gap by examining the interacting effects of aboveground insect pollination and belowground arbuscular mycorrhizal fungi (AMF) inoculation on

\footnotetext{
* Corresponding author.

E-mail address: ke.chen@wur.nl (K. Chen).
} 
crop yield of raspberry (Rubus idaeus L.) and how this is affected by different fertilizer application levels.

AMF are able to form symbiotic associations with about $72 \%$ of all vascular terrestrial plants (Smith and Read, 2010; Brundrett and Tedersoo, 2018), including the majority of field crops (Plenchette et al., 2005). AMF provide a range of services to plants, such as facilitating mineral nutrient uptake (mainly phosphorus and nitrogen), enhancing disease resistance and stress tolerance, and improving soil structure (Smith and Read, 2010; Chen et al., 2018). AMF colonization of crop plants can significantly increase crop yield (Zhang et al., 2019). However, current agricultural practices, such as high fertilizer inputs and tillage, are likely to inhibit AMF growth, and root colonization might currently be suboptimal in many agricultural systems (Bhadalung et al., 2005; Jansa et al., 2006; Verbruggen et al., 2013). Farmers might actively manage for increased AMF colonization through reduced tillage (Bowles et al., 2017), or by inoculating the soil or seedlings, but whether this is effective for crop yield is less studied (Tamburini et al., 2020). Interestingly, AMF might also have indirect effects on crop production as the presence of AMF in plant roots can moderate the behaviour of other service-providing species groups. For example, Gange and Smith (2005) found that plants with AMF can significantly increase pollinator visitation frequency, which indicates that AMF and pollinator service delivery might interactively shape crop yield (Wolfe et al., 2005; Saini et al., 2019). However, AMF might also provide disservices to the host plant's growth and development, for example by reducing phosphorus uptake (Smith et al., 2004). Whether the net balance of AMF inoculation is positive for raspberry crop yield, and how this varies under different levels of fertilizer application is unknown.

Pollinators are important ecosystem service providers as they enhance yields in two-thirds of the leading global crops, and contribute to $35 \%$ of the global food production (Klein et al., 2007). Pollination might alter a number of interrelated qualitative and quantitative yield parameters such as fruit/seed set and size (Bommarco et al., 2012; Klatt et al., 2014; Fijen et al., 2018). However, the positive effect of pollination on a particular yield parameter does not automatically result in a higher total crop yield. For example, in sunflower (Helianthus annuus L.) increasing insect pollination can contribute to higher seed set but with smaller seeds resulting in the same overall yield (Tamburini et al., 2017), probably because yield is constrained by other factors, such as nutrient availability (Garibaldi et al., 2018). Particularly for high-revenue fruit crops like raspberry (Daubeny and Kempler, 2003), both yield quantity and quality are important for farmers. To make more reliable predictions of the benefits of ecological intensification for agriculture, it is therefore important to gain insight into how effects of insect pollination shape crop yield through these intercorrelated yield parameters, and how this is affected by other ecosystem services such as those provided by AMF, or management practices such as fertilizer application.

Here, we experimentally manipulated insect pollination, AMF inoculation and nutrient availability on raspberry crop plants in a randomized complete block design to explore whether and how AMF inoculation, insect pollination and fertilizer application interactively affect crop yield, which to our knowledge has not been studied before. The main objectives of this study were (i) to test the effects of AMF inoculation and fertilizer application rates on pollinator visitation, (ii) to examine the effects of pollination and AMF inoculation on five yield quality and quantity parameters and how their effects are influenced by fertilizer application, and (iii) to explore the pathways explaining the relationships among the variables. The insights obtained in our study might help advance our understanding of whether and how we can integrate different ecosystem services into farming practices to make agriculture more sustainable.

\section{Materials and methods}

(a) Study system

We used raspberry as our study crop, which is an increasingly important fruit crop with a global production value of $\$ 1.5$ billion in 2018 (FAO, 2018). We used the cultivar 'Tulameen', which is among the most popular raspberry cultivars worldwide due to its high marketable quality, mainly the appearance and flavour (Aprea et al., 2009). It is a self-compatible cultivar, but high-quality fruit production nevertheless benefits from visitation by insect pollinators (Daubeny and Kempler, 2003; Chen et al., 2021). The study was carried out on an experimental field of Wageningen University \& Research in Wageningen, the Netherlands (51 ${ }^{\circ} 59^{\prime} 47^{\prime \prime} \mathrm{N}, 5^{\circ} 39^{\prime} 36^{\prime \prime} \mathrm{E}$; $780 \mathrm{~mm}$ mean annual precipitation, $9.4{ }^{\circ} \mathrm{C}$ mean annual temperature).

(b) Experimental design

In August 2019, we purchased raspberry plants with a height of ca. $60 \mathrm{~cm}$ from a local fruit tree supplier. To ensure that all plants were exposed to the same soil conditions, we carefully washed away any soil adhering to the roots of raspberry plants prior to transplanting. Each plant was then planted into a 10-litre plastic pot (upper diameter $28 \mathrm{~cm}$, holes in the bottom for drainage but covered with root cloth to minimize root growth out of the pot), and filled with un-sterilized former agricultural soil (SOM content: $1.95 \%$, available $\mathrm{N}: 14.0 \mathrm{mg} / \mathrm{kg}$, available $\mathrm{P}: 0.6 \mathrm{mg} / \mathrm{kg}$, available K: $19.4 \mathrm{mg} / \mathrm{kg}$ ). Soils were not sterilized to reflect realworld conditions in agricultural fields where plants can be colonized by AMF already present in the agricultural soil.

As our AMF treatment, we added either alive inoculum (inoculated) or sterilized inoculum (non-inoculated). We used the commercially available Rhizophagus intraradices inoculum (MYKOS ${ }^{\circledR}$ Xtreme Gardening, Canada). To sterilize the inoculum for our non-inoculated treatment, we autoclaved it at $121{ }^{\circ} \mathrm{C}$ for two hours (Changey et al., 2019). During transplantation, we gave each plant two tablespoons of inoculum or sterilized inoculum spread evenly on the roots.

The fertilizer treatments comprised four levels: 0, 33, 66 and $99 \mathrm{~kg}$ $\mathrm{ha}^{-1}$ of $\mathrm{N}$ per year. The fertilizer levels were selected to include the range from no to optimum $\mathrm{N}$ inputs, as the recommended annual fertilizer $\mathrm{N}$ application rates for raspberry range from 45 to $85 \mathrm{~kg} / \mathrm{ha}$ (Strik, 2005). The annual dose was divided into three applications: the first application at two weeks after transplanting (October 30, 2019), the second application at the bud break (March 16, 2020) and the last application just before flower opening (April 24, 2020). We selected a local commonly used fertilizer for the experiment, containing $10.80 \% \mathrm{~N}, 13.44 \% \mathrm{~K}$, $5.89 \%$ P, and 7.20\% S (CropSolutions Co., Perth, UK).

Our experimental site is known to host pollinators, mainly wild bumblebees and managed honey bees, in sufficient densities to result in an optimal fruit set of raspberry plants (Chen et al., 2021). To examine the effect of insect pollination, we excluded pollinators from half of the plants and used open-pollinated plants as positive controls. We covered every plant of the pollinator exclusion treatments with a white semi-transparent mesh bag (mesh size $0.1 \mathrm{~mm}$ ) before the onset of flowering and kept plants covered throughout the flowering period. The mesh bags allowed wind pollination but excluded all insect visitors. To avoid predation of the developing fruits, we covered all plants after flowering with the mesh bags until harvest.

We used a randomized complete block design with AMF inoculation (two levels), pollination (two levels) and fertilizer (four levels) fully crossed to measure their individual and interacting effects on raspberry productivity. This resulted in 16 treatment combinations, which were randomly assigned to individual raspberry plants and replicated in five blocks, bringing the total to 80 experimental plants. Potted plants were spaced one meter apart both within and between rows and dug into the soil to protect the roots from extreme temperatures. All plants received equal and ample irrigation, and weeds were regularly removed by hand. 


\subsection{Measurements}

For each plant of the open pollination treatment, we conducted tenminute pollinator censuses from May 12-27 th 2020 to see if the AMF inoculation and fertilizer treatments affected the pollinator visitation rate. We randomly observed plants ten times on different days (morning or afternoon), and only during sunny or slightly cloudy days and with low wind velocity, following the focal point observation method (Fijen and Kleijn, 2017). We only recorded flower visitors that contacted anthers or stigmas of flowers per plant. All flower visitors were identified on the wing, with bees identified to species level and other pollinators to order level. From June 15 onward, we harvested ripe berries every other day and weighed the fresh weight of each berry in the lab. Additionally, we counted the wilted and aborted flowers of each plant.

To assess whether AMF inoculation results in higher final AMF colonisation rate compared to non-inoculated plants, we collected fine roots ( $<1 \mathrm{~mm}$ in diameter) after the harvest of all the plants. Firstly, two grams of roots from each plant were cleared and stained following a protocol adjusted from Koske and Gemma (1989). AMF colonization rate was subsequently measured following the gridline intersect method (Giovannetti and Mosse, 1980). AMF colonization rate was calculated as the percentage of the colonised intersections of the total observed intersections.

\subsection{Data analysis}

Four plants died over winter prior to fruit production, resulting in a dataset for 76 plants (Table S1). Prior to analyses, single berry weight was averaged per plant to avoid pseudoreplication. Total flower number per plant was calculated as the sum of the total fruit number and the total number of flowers that did not develop into fruits (e.g. wilted or aborted flowers). Per-plant fruit set was calculated by dividing the fruit number by the total flower number and expressed as a percentage.

We fitted linear mixed-effects models to quantify the relations between the experimental treatments and response variables. We fitted separate full models for each of the response variables flower number, fruit number, fruit set (\%), single berry weight ( $\mathrm{g} /$ fruit) and total yield ( $\mathrm{g}$ /plant), and included "block" as a random factor in all models. Independent variables included pollination, AMF inoculation, fertilizer application rate and all their possible interactions (i.e. all two- and three-way interactions). We also included a quadratic term for fertilizer application rate to test for non-linear relations between fertilizer levels and raspberry production (Tamburini et al., 2017). The full models were simplified by removing non-significant predictors (backward elimination) using likelihood ratio tests with removal thresholds of $p>0.05$, until the resulting minimum adequate model consisted only of variables that contributed significantly to the outcome (Zuur et al., 2009). Finally, we tested the effects of AMF inoculation and fertilizer treatments on the average pollinator visitation rate (visitors $/ 10 \mathrm{~min}$ ), including the quadratic term for fertilizer application rate, and their interactions, and "block" as a random factor. For this analysis we only used the open pollination treatment plants. The models were built using the function lme() in the nlme package with the maximum likelihood estimation method (Pinheiro et al., 2019). Statistical assumptions of normality and homoscedasticity of model residuals were inspected visually through diagnostic plots using the function plotresid() in the RVAideMemoire package. All analyses were performed in R (R Core Team, 2020).

\section{Results}

\subsection{Total visits and flower visitation rate}

Altogether, 682 individual pollinators were observed, divided over seven taxa: Apis mellifera (471 individuals), Bombus terrestris congl. (132 individuals, including $B$. terrestris and $B$. lucorum due to overlapping morphology, cf. Williams et al., 2012), B. pascuorum (55 individuals),
B. lapidarius (13 individuals), B. pratorum (7 individuals), hoverfly (3 individuals) and B. sylvestris (1 individual). AMF inoculation and fertilizer application interactively influenced pollinator visitation rate per plant (Table 1). Pollinator visitation rate increased with fertilizer levels, and was higher for plants that had been inoculated with AMF than for non-inoculated plants at intermediate fertilizer application rates, but not at low or high fertilizer application rates (Table 1, Fig. 1). Besides, the pollinator visitation rate was strongly correlated with the number of flowers per plant (Fig. S1).

\subsection{Flower number, fruit set and fruit number}

The number of flowers per plant increased independently by both factors that (potentially) influence the nutrient acquisition, i.e. fertilizer inputs and AMF inoculation. Fertilizer inputs linearly increased flower number (Table 2), with plants receiving $99 \mathrm{~kg} \mathrm{~N} \cdot \mathrm{ha}^{-1}$ producing $105 \%$ (mean \pm SE: $57.7 \pm 2.0$ ) more flowers than the unfertilized plants (28.1 \pm 2.1 , Fig. 2a). Compared to the non-inoculated plants, AMF inoculation increased flower number by $33 \%$ (from $36.6 \pm 4.5$ to $48.7 \pm 4.5$, Table 2, Fig. 2b). There was a near-significant interaction $(\mathrm{P}=0.059)$ between the effect of AMF inoculation and the quadratic term of fertilizer application rate, with AMF inoculated plants receiving intermediate fertilizer application rates producing the most flowers (Table 2, Fig. S2).

Fruit set was mainly altered by an interaction between the insect pollination and the fertilizer treatment, where pollination benefits were most pronounced at the higher fertilizer application rates (significant pollination $\times$ fertilizer interaction; Table 2). From the lowest to the highest level, fertilizer application increased the fruit set of openpollinated plants by $37 \%$ and had little effect on fruit set in bagged plants (Fig. 2c). Fruit set was not affected by AMF inoculation (Fig. 2d).

Pollination and fertilizer application rate interactively affected fruit number with open-pollinated plants receiving $99 \mathrm{~kg} \mathrm{~N} \cdot \mathrm{ha}^{-1}$ producing $162 \%(51.7 \pm 2.0)$ more fruits than unfertilized plants $(19.7 \pm 2.0)$. This increase was only $53 \%$ when pollinators were excluded (Table 2, Fig. 2e). Additionally, AMF inoculation independently increased fruit number by $35 \%$ (from $25.5 \pm 3.7$ to $34.3 \pm 3.7$, Fig. 2 f).

\subsection{Single berry weight and yield}

Increasing fertilizer application rates influenced single berry weight interactively with AMF inoculation treatments, with a much more pronounced positive response in AMF inoculated plants compared to the non-inoculated plants (Table 2, Fig. 3). Pollination treatments did not influence single berry weight (Table 2).

The total yield is essentially the product of per-plant fruit number and single berry weight. However, total yield largely reflected effects of treatments on total fruit number, albeit stronger, while the significant interaction of AMF inoculation and fertilizer application on single berry weight was not reflected in the pattern for total yield (Table 2, Fig. 4). Total yield was positively related to fertilizer application rate, but these

\section{Table 1}

Effects of arbuscular mycorrhizal fungi (AMF; inoculated vs non-inoculated) and fertilizer application rates $\left(0,33,66,99 \mathrm{~kg} \mathrm{~N} \cdot \mathrm{ha}^{-1} \cdot \mathrm{year}^{-1}\right)$ on flower visitation rate (open-pollinated plants only, $\mathrm{n}=37$ ). Only the estimates from the minimum adequate model were included. All analyses were performed using a linear mixed-effects model. Bold values represent significant effects $(\mathrm{P}<0.05)$.

\begin{tabular}{llll}
\hline & \multicolumn{2}{l}{ Flower visitation rate } & \\
\cline { 2 - 4 } & Estimate & $\chi^{2}{ }_{(1)}$ & $\mathrm{P}$ \\
\hline AMF & -0.299 & 2.096 & 0.148 \\
Fertilizer & -0.022 & 5.394 & $\mathbf{0 . 0 2 0}$ \\
Fertilizer2 & 0.000 & 0.396 & 0.529 \\
AMF:fertilizer & 0.041 & 0.284 & 0.594 \\
AMF:fertilizer² & 0.000 & 5.234 & $\mathbf{0 . 0 2 2}$ \\
\hline
\end{tabular}




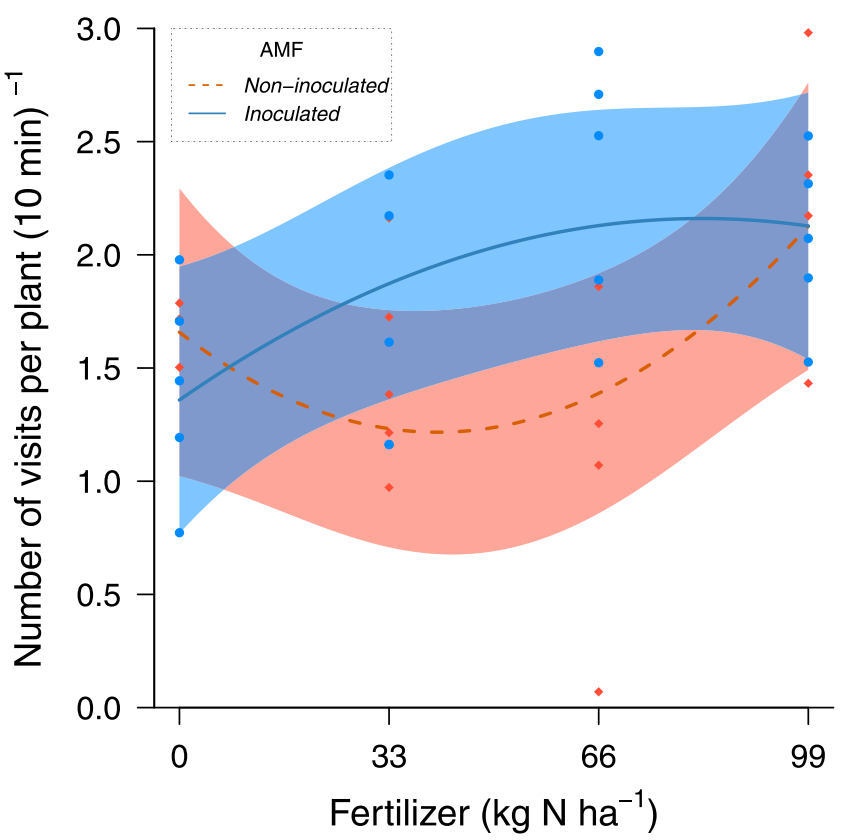

Fig. 1. Interactive effects of AMF inoculation and fertilizer application rates on pollinator visitation rate (number of visits per $10 \mathrm{~min}$ ) of raspberry. The lines are predicted by the minimum adequate model; shadings show the $95 \%$ confidence interval, and points represent partial residuals.

effects were much more pronounced in open-pollinated plants than in plants from which pollinators had been excluded; plants with insect pollination produced $90 \%$ more yield than bagged plants under our highest fertilizer input level $(83.8 \pm 3.0$ and $44.2 \pm 2.5 \mathrm{~g}$ separately, Fig. 4a). On top of that, the yield of AMF inoculated plants significantly increased by $43 \%$ compared to the non-inoculated plants (from $35.1 \pm 5.1-50.2 \pm 5.1 \mathrm{~g}$, Fig. 4b). Under the highest fertilizer input, raspberry plants with open pollination and AMF inoculation produced the highest yield, on average $90.4 \pm 2.0 \mathrm{~g}$ berries, which was $135 \%$ more than the yield of plants receiving only the fertilizer application $(38.5 \pm 2.0 \mathrm{~g})$.

\subsection{AMF colonization rate}

We found no significant difference between AMF colonization rate of the AMF inoculation or fertiliser treatments at the end of the experiment (mean \pm SE: $59.6 \% \pm 1.5 \%$ ). This was likely because all plants had been well colonized by either inoculated AMF or indigenous AMF in the soils after 12 months' growth (Ortas, 2012; An-Dong et al., 2013).

\section{Discussion}

Our results indicate positive effects of AMF inoculation on raspberry yield that were independent of the effects of pollination and fertilizer application, and positive synergistic effects of pollination and fertilizer inputs on yield. AMF inoculation enhanced the fruit-producing potential of plants by increasing the number of flowers per plant, independent from fertilizer. Insect pollination subsequently increased the likelihood that these flowers developed into fruits but only when plants received enough fertilizers. This probably suggests that poorly fertilized plants have insufficient resources for maximum fruit set. Interestingly, at intermediate fertilizer levels, AMF inoculation also enhanced pollinator visitation rates suggesting intricate indirect effects of one ecosystem service on another. Our findings imply that the simultaneous management of below- and aboveground ecosystem services can substantially increase the yield-enhancing effects of fertilizer application and represent a compelling example of ecological enhancement (i.e. enhancing

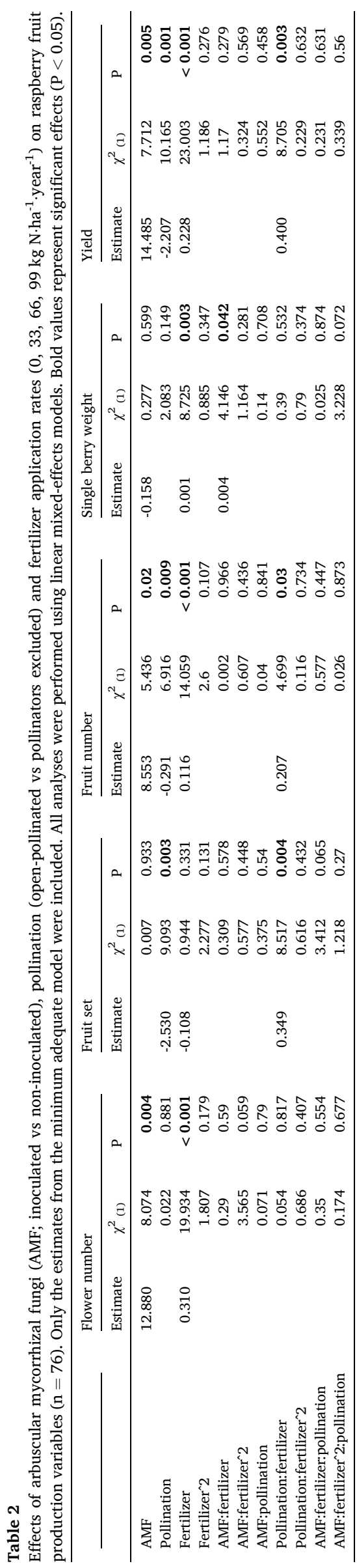



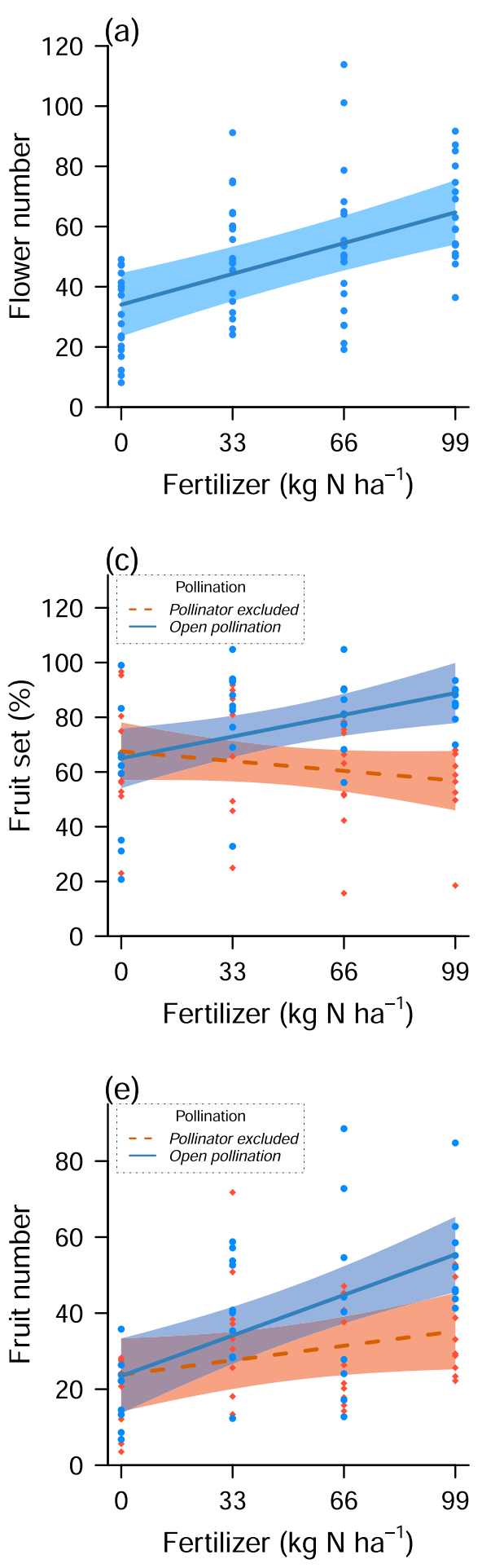

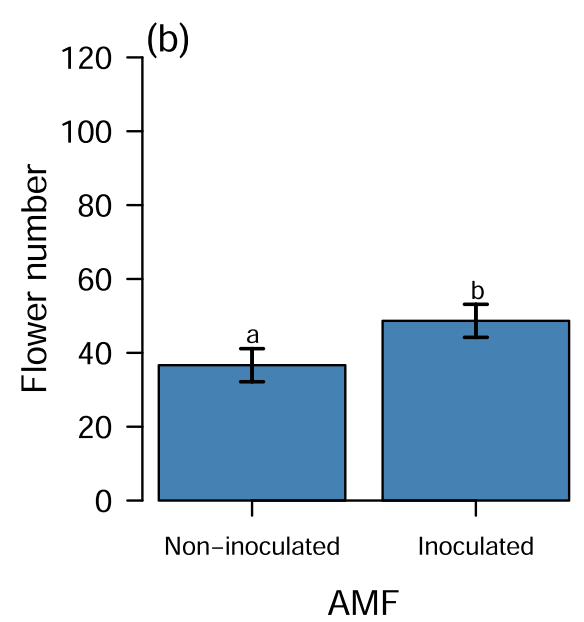

Fig. 2. Effects of AMF inoculation, pollination and fertilizer application rates on flower number ( $a$ and b), fruit set (c and d), and fruit number (e and $f$ ) per plant. Graphs show predicted values of the minimum adequate models; panel (d) shows non-significant estimated mean fruit set for AMF treatments as calculated in a model including AMF treatment $(\mathrm{p}=0.93)$ and the minimum adequate model parameters, and is shown for completeness. Different letters in barographs indicate significant differences among AMF treatments. Shadings show the 95\% confidence interval, and points represent partial residuals; error bars show $\pm 1 \mathrm{SE}$.

(d)

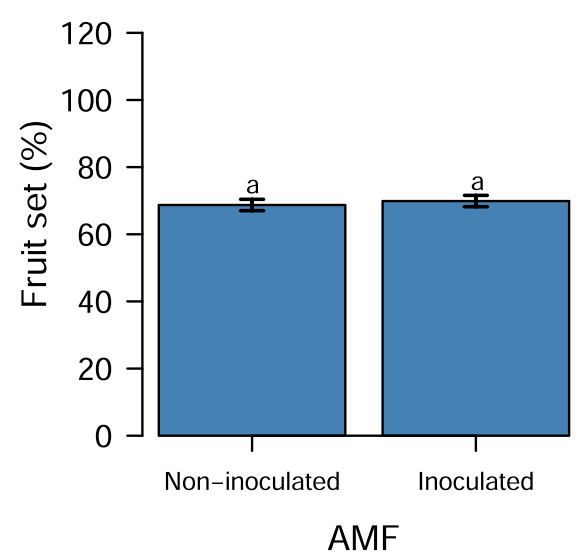

(f)

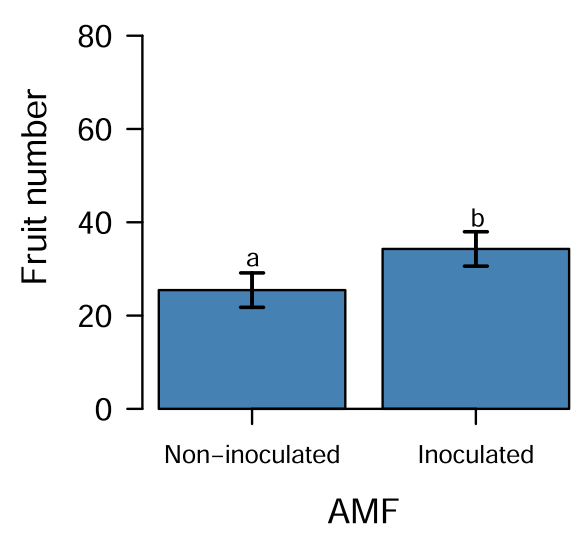

yield by increasing ecosystem service delivery without increasing agricultural inputs) sensu Bommarco et al. (2013).

\subsection{AMF inoculation contributing to raspberry yield directly and indirectly}

AMF inoculation contributed to raspberry yield mainly through enhancing the number of flowers and by allowing plants to develop larger fruits, as AMF inoculation did not affect fruit set. The 35\% increase in fruit numbers of plants inoculated with AMF was very similar to the $33 \%$ increase in flower numbers of AMF inoculated plants,

suggesting that AMF inoculation did not have a direct effect on fruit number but mostly on flower number. The effect on flower number might be due to the ability of AMF to increase plant nutrient concentrations (especially $\mathrm{P}$ and $\mathrm{K}$ ) and to raise hormone levels stimulating bud-formation which have both been observed to lead to the development of larger numbers of flowers (Long et al., 2010). The positive effect of AMF inoculation on fruit size has been found in strawberry as well (Bona et al., 2015), but in our case the benefits were only expressed under ample fertilizer inputs. Possibly, at low fertilizer application rates, soil nutrient availability was the main limiting factor, while at higher fertilizer application rates, plant nutrient uptake capacity became a 


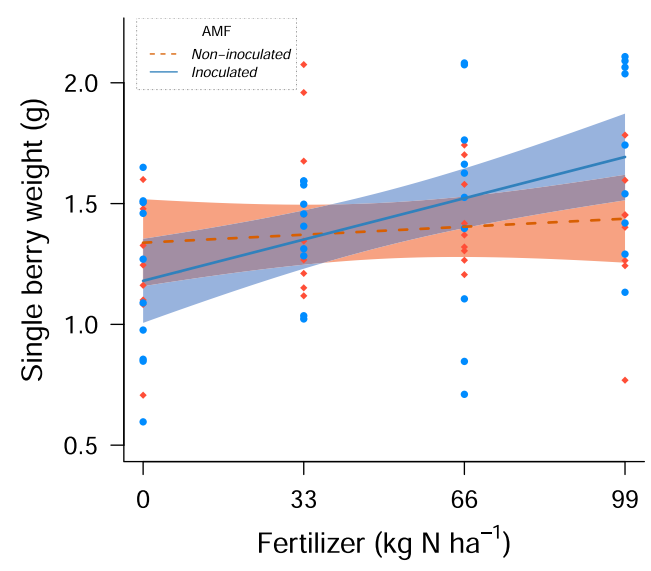

Fig. 3. Interactive effects of AMF inoculation and fertilizer application rates on average single berry weight $(\mathrm{g})$ per plant. The lines are predicted by the minimum adequate model; shadings show the $95 \%$ confidence interval, and points represent partial residuals.

more limiting factor which AMF are known to improve (Wang et al., 2018). Surprisingly, when no fertilizer was applied, AMF-inoculated plants developed slightly smaller fruits than the plants that had not been inoculated, which could be the result of the competition for $\mathrm{N}$ with the host (Wang et al., 2018; Ingraffia et al., 2020). The interaction between AMF inoculation and fertilizer application did not carry over into the final yield. Raspberry plants are readily colonized by AMF (Taylor and Harrier, 2000) and regardless of treatment, all plants had formed associations with AMF to some degree by the end of the study. Our results, therefore, provide a conservative estimate of the potential contribution of AMF to raspberry crops.

Interestingly, our results indicate that AMF inoculation can also indirectly contribute to raspberry production through increasing pollinator visitation rate and thus pollination. Pollination has been shown to be an important factor limiting raspberry production, even in selfcompatible cultivars like the one used in the present study (Chen et al., 2021). In our study, AMF inoculation and fertilizer inputs interactively shaped pollinator visitation rate per plant, and the pattern resembled their near-significant interaction on flower number ( $p=0.059$, Fig. S2), which is an important plant trait to affect attractiveness to pollinators (Gange and Smith, 2005). Therefore, it seems likely that the effects of AMF inoculation on pollinator visitation rate operated through their influence on flower number. However, we cannot rule out the possibility that AMF inoculation also influenced pollinator visitation rate through altering the composition of nectar and pollen (Somme et al., 2015; Bennett and Meek, 2020).

\subsection{Synergistic effects of insect pollination and fertilizer on raspberry production}

Insect pollination and fertilizer inputs showed synergistic effects on raspberry yield. The possible pathway to explain the interacting effects starts with the positive effect of fertilizer on flower number, which simultaneously increased both the number of flowers that can potentially be pollinated and developed into fruits, as well as increased the attractiveness of the plant to pollinators (Conner and Rush, 1996). Increased pollinator visitation rate in turn improved fruit set of the plants in the open pollination because increased insect pollination generally enhances the transfer of pollen for ovule fertilization (Sáez et al., 2020). Interestingly, the benefits of insect pollination and fertilizer inputs seem to be depending on each other, as in the absence of the one, the benefits of the other diminish. For example, in the absence of fertilizer inputs, pollination benefits on fruit set are negligible, suggesting that nutrient availability limited the potential benefits of insect pollination to develop additional fruits (Garratt et al., 2018). Similarly, in the absence of insect pollination, solely increasing fertilizer inputs did not increase fruit set at all. This suggests that raspberry is probably limited by multiple 'resources' at the same time (Garibaldi et al., 2018), and that both need to be optimized to reach the highest raspberry crop yield. It also indicates that in our study system, ecosystem service benefits critically depend on the right management of external inputs and thus cannot easily replace them.

Because insect pollination did not influence single berry weight, the pollination-induced effects on fruit set carried over into similar effects on fruit number (Fig. 2e) and eventually the yield (Fig. 4a). In a previous study using the same experimental system we did find positive effects of insect pollination on raspberry fruit size but not on fruit number (Chen et al., 2021). Plants have multiple ways to invest their most limiting resources (compensation mechanism; (Garratt et al., 2018)), which suggests that if one ecosystem service partially removes one limitation (e.g. nutrient-constrained flower development) this might impose new limitations to a subsequent process (e.g. nutrient-constrained drupelet development of raspberry fruits). However, it is noteworthy that regardless of the exact pathway, insect pollination resulted in substantially increased total raspberry crop yield in both studies.
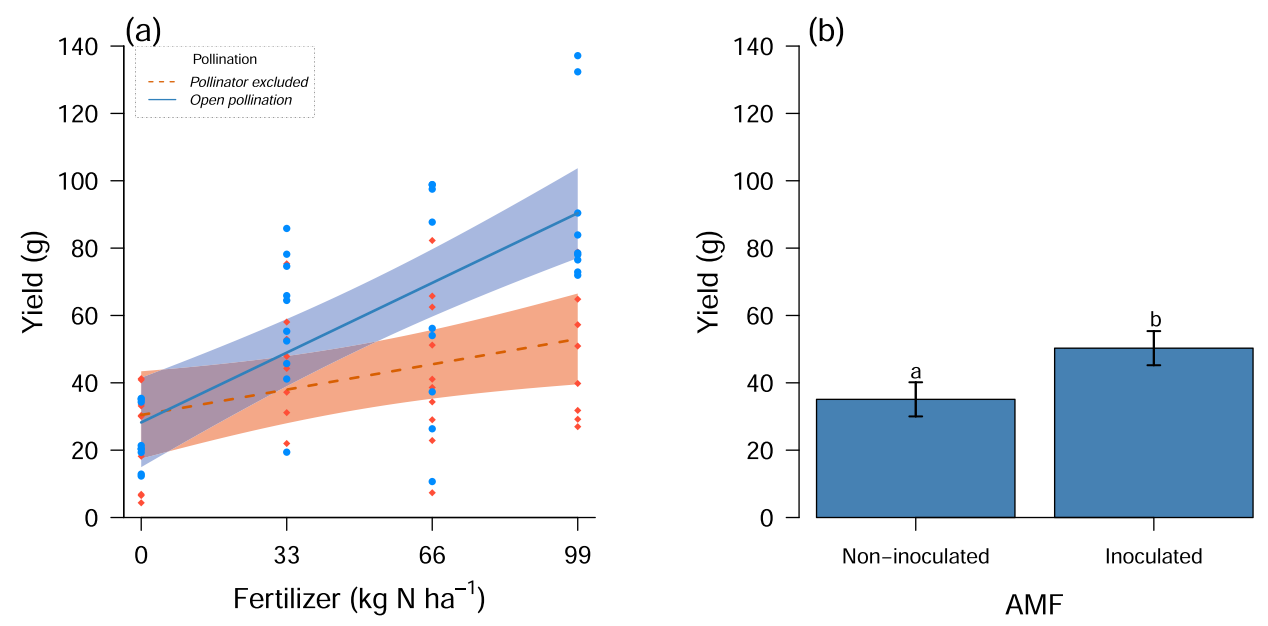

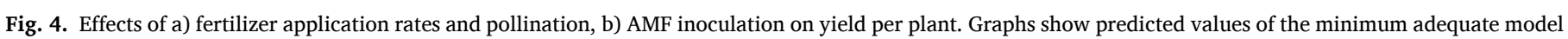

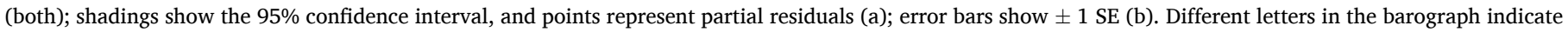
significant differences among AMF treatments. 


\subsection{The potential of capitalizing on ecosystem services in farming systems}

Our results highlight the importance of maintaining ecosystem service providing species in agro-ecosystems. Not only did we find that without pollination and AMF inoculation raspberry yield would be substantially reduced, but yield effects of fertilizer were much less pronounced in the absence of ecosystem services. Agricultural production methods that do not consider potential adverse effects on ecosystem service providing species might risk shifting the system to one that is limited by delivery of ecosystem services rather than by management intensity (Deguines et al., 2014; Fijen et al., 2020). This is not a trivial issue as, for example, AMF colonization might be adversely affected by the application of some types of pesticides (Hernández-Dorrego and Parés, 2010; Hage-Ahmed et al., 2019). A farmer trying to control a disease using fungicides might succeed in minimizing disease damage only to lose the benefits provided by AMF. Our results furthermore suggest that proactively managing for ecosystem services can even increase crop production independently of conventional management practices such as fertilizer application, or can enhance the yield increases due to such practices as here with pollination. Such an approach could address the increasing demands for safe and healthy food that is typically associated with crop production methods that rely on natural processes rather than external inputs (Yiridoe et al., 2005). Here we found additive and synergistic benefits among insect pollination, AMF inoculation and fertilizer inputs. Given that other species groups can have additional yield impacts through, for example, biological pest control or nutrient cycling, the ultimate benefits to agricultural production of capitalizing more on natural processes could be substantially higher.

\section{Declaration of Competing Interest}

The authors declare that they have no known competing financial interests or personal relationships that could have appeared to influence the work reported in this paper.

\section{Acknowledgements}

We thank Lisa Kiel for her kind help with the pollinator observation. We thank Giannis Bagiorgas Kotsakaris, Isa van Lidth de Jeude, Quiniver Tuinder and Szabolcs Szabo for their help in AMF colonization rate measurements. We also thank the anonymous reviewers for their helpful comments and suggestions that improved this manuscript. K.C. was funded by the China Scholarship Council (File No. 201706990023).

\section{Appendix A. Supporting information}

Supplementary data associated with this article can be found in the online version at doi:10.1016/j.agee.2021.107742.

\section{References}

An-Dong, S., Qian, L., HUANG, J.-G., Ling, Y., 2013. Influence of arbuscular mycorrhizal fungi on growth, mineral nutrition and chlorogenic acid content of Lonicera confusa seedlings under field conditions. Pedosphere 23, 333-339.

Aprea, E., Biasioli, F., Carlin, S., Endrizzi, I., Gasperi, F., 2009. Investigation of volatile compounds in two raspberry cultivars by two headspace techniques: solid-phase microextraction/gas chromatography - mass spectrometry (SPME/GC-MS) and proton-transfer reaction - mass spectrometry (PTR-MS). J. Agric. Food Chem. 57, 4011-4018.

Bakhshandeh, S., Corneo, P.E., Mariotte, P., Kertesz, M.A., Dijkstra, F.A., 2017. Effect of crop rotation on mycorrhizal colonization and wheat yield under different fertilizer treatments. Agric. Ecosyst. Environ. 247, 130-136.

Bennett, A.E., Meek, H.C., 2020. The influence of arbuscular mycorrhizal fungi on plant reproduction. J. Chem. Ecol. 46, 707-721.

Bhadalung, N.N., Suwanarit, A., Dell, B., Nopamornbodi, O., Thamchaipenet, A., Rungchuang, J., 2005. Effects of long-term NP-fertilization on abundance and diversity of arbuscular mycorrhizal fungi under a maize cropping system. Plant Soil $270,371-382$.
Bommarco, R., Kleijn, D., Potts, S.G., 2013. Ecological intensification: harnessing ecosystem services for food security. Trends Ecol. Evol. 28, 230-238.

Bommarco, R., Marini, L., Vaissière, B.E., 2012. Insect pollination enhances seed yield, quality, and market value in oilseed rape. Oecologia 169, 1025-1032.

Bona, E., Lingua, G., Manassero, P., Cantamessa, S., Marsano, F., Todeschini, V., Copetta, A., D’Agostino, G., Massa, N., Avidano, L., 2015. AM fungi and PGP pseudomonads increase flowering, fruit production, and vitamin content in strawberry grown at low nitrogen and phosphorus levels. Mycorrhiza 25, 181-193.

Bowles, T.M., Jackson, L.E., Loeher, M., Cavagnaro, T.R., 2017. Ecological intensification and arbuscular mycorrhizas: a meta-analysis of tillage and cover crop effects. J. Appl. Ecol. 54, 1785-1793.

Brundrett, M.C., Tedersoo, L., 2018. Evolutionary history of mycorrhizal symbioses and global host plant diversity. New Phytol. 220, 1108-1115.

Changey, F., Meglouli, H., Fontaine, J., Magnin-Robert, M., Tisserant, B., Lerch, T.Z., Sahraoui, A.L.-H., 2019. Initial microbial status modulates mycorrhizal inoculation effect on rhizosphere microbial communities. Mycorrhiza 29, 475-487.

Chen, M., Arato, M., Borghi, L., Nouri, E., Reinhardt, D., 2018. Beneficial services of arbuscular mycorrhizal fungi-from ecology to application. Front. Plant Sci. 9, 1270.

Chen, K., Fijen, T.P., Kleijn, D., Scheper, J., 2021. Insect pollination and soil organic matter improve raspberry production independently of the effects of fertilizers. Agric. Ecosyst. Environ. 309, 107270.

Conner, J.K., Rush, S., 1996. Effects of flower size and number on pollinator visitation to wild radish, Raphanus raphanistrum. Oecologia 105, 509-516.

Costanza, R., d'Arge, R., De Groot, R., Farber, S., Grasso, M., Hannon, B., Limburg, K., Naeem, S., O'neill, R.V., Paruelo, J., 1997. The value of the world's ecosystem services and natural capital. nature 387, 253-260.

Dainese, M., Martin, E.A., Aizen, M.A., Albrecht, M., Bartomeus, I., Bommarco, R., Carvalheiro, L.G., Chaplin-Kramer, R., Gagic, V., Garibaldi, L.A., 2019. A global synthesis reveals biodiversity-mediated benefits for crop production. Sci. Adv. 5, 5 eaax0121.

Daubeny, H., Kempler, C., 2003. 'Tulameen'red raspberry. J. Am. Pomol. Soc. 57, 42.

Deguines, N., Jono, C., Baude, M., Henry, M., Julliard, R., Fontaine, C., 2014. Large-scale trade-off between agricultural intensification and crop pollination services. Front. Ecol. Environ. 12, 212-217.

FAO, 2018. Value of Agricultural Production. http://www.fao.org/faostat/en/\#data/ QV.

Fijen, T.P., Kleijn, D., 2017. How to efficiently obtain accurate estimates of flower visitation rates by pollinators. Basic Appl. Ecol. 19, 11-18.

Fijen, T.P., Scheper, J.A., Boom, T.M., Janssen, N., Raemakers, I., Kleijn, D., 2018. Insect pollination is at least as important for marketable crop yield as plant quality in a seed crop. Ecol. Lett. 21, 1704-1713.

Fijen, T.P., Scheper, J.A., Vogel, C., van Ruijven, J., Kleijn, D., 2020. Insect pollination is the weakest link in the production of a hybrid seed crop. Agric. Ecosyst. Environ. 290, 106743.

Gange, A.C., Smith, A.K., 2005. Arbuscular mycorrhizal fungi influence visitation rates of pollinating insects. Ecol. Entomol. 30, 600-606.

Garibaldi, L.A., Andersson, G.K., Requier, F., Fijen, T.P., Hipólito, J., Kleijn, D., PérezMéndez, N., Rollin, O., 2018. Complementarity and synergisms among ecosystem services supporting crop yield. Glob. Food Secur. 17, 38-47.

Garratt, M.P., Bishop, J., Degani, E., Potts, S.G., Shaw, R.F., Shi, A., Roy, S., 2018. Insect pollination as an agronomic input: strategies for oilseed rape production. J. Appl. Ecol. 55, 2834-2842.

Giovannetti, M., Mosse, B., 1980. An evaluation of techniques for measuring vesicular arbuscular mycorrhizal infection in roots. New Phytol. 84, 489-500.

Hage-Ahmed, K., Rosner, K., Steinkellner, S., 2019. Arbuscular mycorrhizal fungi and their response to pesticides. Pest Manag. Sci. 75, 583-590.

Hernández-Dorrego, A., Parés, J.M., 2010. Evaluation of some fungicides on mycorrhizal symbiosis between two Glomus species from commercial inocula and Allium porrum L. seedlings. Span. J. Agric. Res. 8, 43-50.

Ingraffia, R., Amato, G., Sosa-Hernández, M.A., Frenda, A.S., Rillig, M.C., Giambalvo, D., 2020. Nitrogen type and availability drive mycorrhizal effects on wheat performance, nitrogen uptake and recovery, and production sustainability. Front. Plant Sci. 11, 760.

IPBES, 2016. In: Potts, S.G., Imperatriz-Fonseca, V., Ngo, H.T. (Eds.), The Assessment Report of the Intergovernmental Science-Policy Platform on Biodiversity and Ecosystem Services on Pollinators, Pollination and Food Production. Secretariat of the Intergovernmental Science-Policy Platform on Biodiversity and Ecosystem Services, Bonn, Germany, p. 552.

Jansa, J., Wiemken, A., Frossard, E., 2006. The Effects of Agricultural Practices on Arbuscular Mycorrhizal Fungi. In: Geological Society, 266. Special Publications, London, pp. 89-115.

Klatt, B.K., Holzschuh, A., Westphal, C., Clough, Y., Smit, I., Pawelzik, E., Tscharntke, T., 2014. Bee pollination improves crop quality, shelf life and commercial value. Proc. Biol. Sci. 281, 20132440.

Kleijn, D., Bommarco, R., Fijen, T.P., Garibaldi, L.A., Potts, S.G., van der Putten, W.H., 2019. Ecological intensification: bridging the gap between science and practice. Trends Ecol. Evol. 34, 154-166.

Klein, A.-M., Vaissiere, B.E., Cane, J.H., Steffan-Dewenter, I., Cunningham, S.A., Kremen, C., Tscharntke, T., 2007. Importance of pollinators in changing landscapes for world crops. Proc. R. Soc. B Biol. Sci. 274, 303-313.

Koske, R.E., Gemma, J.N., 1989. A modified procedure for staining roots to detect VA mycorrhizas. Mycol. Res. 92, 486-488.

Long, L.-K., Yao, Q., Huang, Y.-H., Yang, R.-H., Guo, J., Zhu, H.-H., 2010. Effects of arbuscular mycorrhizal fungi on zinnia and the different colonization between Gigaspora and Glomus. World J. Microbiol. Biotechnol. 26, 1527-1531. 
Ortas, I., 2012. The effect of mycorrhizal fungal inoculation on plant yield, nutrient uptake and inoculation effectiveness under long-term field conditions. Field Crops Res. 125, 35-48.

Pinheiro, J., Bates, D., DebRoy, S., Sarkar, D., Team, R.C., 2019. nlme: Linear and Nonlinear Mixed Effects Models.

Plenchette, C., Clermont-Dauphin, C., Meynard, J., Fortin, J., 2005. Managing arbuscular mycorrhizal fungi in cropping systems. Can. J. Plant Sci. 85, 31-40.

Pywell, R.F., Heard, M.S., Woodcock, B.A., Hinsley, S., Ridding, L., Nowakowski, M., Bullock, J.M., 2015. Wildlife-friendly farming increases crop yield: evidence for ecological intensification. Proc. R. Soc. B Biol. Sci. 282, 20151740.

R Core Team, 2020. R: A Language and Environment for Statistical Computing. R Foundation for Statistical Computing.

Sáez, A., Aizen, M.A., Medici, S., Viel, M., Villalobos, E., Negri, P., 2020. Bees increase crop yield in an alleged pollinator-independent almond variety. Sci. Rep. 10, 1-7.

Saini, I., Aggarwal, A., Kaushik, P., 2019. Inoculation with mycorrhizal fungi and other microbes to improve the morpho-physiological and floral traits of Gazania rigens (L.) gaertn. Agriculture 9, 51.

Smith, S.E., Read, D.J., 2010. Mycorrhizal Symbiosis. Academic press.

Smith, S.E., Smith, F.A., Jakobsen, I., 2004. Functional diversity in arbuscular mycorrhizal (AM) symbioses: the contribution of the mycorrhizal P uptake pathway is not correlated with mycorrhizal responses in growth or total P uptake. New Phytol. 162, 511-524.

Somme, L., Vanderplanck, M., Michez, D., Lombaerde, I., Moerman, R., Wathelet, B. Wattiez, R., Lognay, G., Jacquemart, A.-L., 2015. Pollen and nectar quality drive the major and minor floral choices of bumble bees. Apidologie 46, 92-106.

Strik, B.C., 2005. A review of nitrogen nutrition of Rubus. IX International Rubus and Ribes Symposium 777, pp. 403-410.

Tamburini, G., Bommarco, R., Kleijn, D., van der Putten, W.H., Marini, L., 2019. Pollination contribution to crop yield is often context-dependent: A review of experimental evidence. Agric. Ecosyst. Environ. 280, 16-23.
Tamburini, G., Bommarco, R., Wanger, T.C., Kremen, C., van der Heijden, M.G., Liebman, M., Hallin, S., 2020. Agricultural diversification promotes multiple ecosystem services without compromising yield. Sci. Adv. 6, 6 eaba1715.

Tamburini, G., Lami, F., Marini, L., 2017. Pollination benefits are maximized at intermediate nutrient levels. Proc. Biol. Sci. 284, 284.

Taylor, J., Harrier, L., 2000. A comparison of nine species of arbuscular mycorrhizal fungi on the development and nutrition of micropropagated Rubus idaeus L. cv. Glen Prosen (Red Raspberry). Plant Soil 225, 53-61.

Verbruggen, E., van der Heijden, M.G., Rillig, M.C., Kiers, E.T., 2013. Mycorrhizal fungal establishment in agricultural soils: factors determining inoculation success. New Phytol. 197, 1104-1109.

Wang, X.-X., Wang, X., Sun, Y., Cheng, Y., Liu, S., Chen, X., Feng, G., Kuyper, T.W., 2018. Arbuscular mycorrhizal fungi negatively affect nitrogen acquisition and grain yield of maize in a N deficient soil. Front. Microbiol. 9, 418.

Williams, P.H., Brown, M.J., Carolan, J.C., An, J., Goulson, D., Aytekin, A.M., Best, L.R., Byvaltsev, A.M., Cederberg, B., Dawson, R., 2012. Unveiling cryptic species of the bumblebee subgenus Bombus s. str. worldwide with COI barcodes (Hymenoptera: Apidae). Syst. Biodivers. 10, 21-56.

Wolfe, B.E., Husband, B.C., Klironomos, J.N., 2005. Effects of a belowground mutualism on an aboveground mutualism. Ecol. Lett. 8, 218-223.

Yiridoe, E.K., Bonti-Ankomah, S., Martin, R.C., 2005. Comparison of consumer perceptions and preference toward organic versus conventionally produced foods: a review and update of the literature. Renew. Agric. Food Syst. 20, 193-205.

Zhang, S., Lehmann, A., Zheng, W., You, Z., Rillig, M.C., 2019. Arbuscular mycorrhizal fungi increase grain yields: a meta-analysis. New Phytol. 222, 543-555.

Zuur, A., Ieno, E.N., Walker, N., Saveliev, A.A., Smith, G.M., 2009. Mixed Effects Models and Extensions in Ecology With R. Springer Science \& Business Media. 